\title{
The Prevalence of Endoparasites of Free Ranging Cats (Felis catus) from Urban Habitats in Southern Poland
}

\author{
Izabela A. Wierzbowska ${ }^{1}$, Sławomir Kornaś ${ }^{2}$, Aleksandra M. Piontek ${ }^{1, *}$ and Kaja Rola ${ }^{3}$ \\ 1 Institute of Environmental Sciences, Faculty of Biology of Jagiellonian University, 7 Gronostajowa Str., \\ 30-387 Kraków, Poland; i.wierzbowska@uj.edu.pl \\ 2 Faculty of Animal Breeding and Biology, University of Agriculture in Kraków, 24/28 Mickiewicza Av., \\ 30-059 Kraków, Poland; s.kornas@ur.krakow.pl \\ 3 Institute of Botany, Faculty of Biology of Jagiellonian University, 3 Gronostajowa str., 30-387 Kraków, Poland; \\ kaja.skubala@uj.edu.pl \\ * Correspondence: olka.piontek@doctoral.uj.edu.pl; Tel.: +48-012-664-5157
}

Received: 29 March 2020; Accepted: 21 April 2020; Published: 24 April 2020

Simple Summary: Free ranging domestic cats are common in urban and suburban habitats and may cause a threat of disease transmission to other pets, wildlife and humans. We investigated the occurrence of endoparasites in cats in Kraków city, Southern Poland, based on examination of road-killed individuals. More than half of the cats were infected with at least one of seven identified parasites. Cats from suburban areas were more likely to be infected than cats from the city core. Our study supports the results from other studies, showing that cats may serve as a significant source of zoonotic transmission.

\begin{abstract}
Growing urbanization leads to an increased risk of parasite spread in densely inhabited areas. Free-ranging cats can be locally numerous and come into frequent contact with both wildlife and humans. Cats are thus expected to contribute to parasitic disease transmission. In our study, we investigated the prevalence of endoparasites in free ranging cats in urban areas of Kraków city, based on necropsy of road-killed cats in relation to sex and diet of cat, season and habitat type. We found that $62 \%$ of 81 cats were infected with endoparasites with Toxocara cati being the most prevalent. In total, we identified seven parasite species. The number of parasite species was higher in suburban habitats and aside from Eucoleus aerophilus the prevalence of all parasites was higher in cats from suburban areas than in the individuals living in the city urban core. The prey of examined cats included mostly rodents, followed by soricomorphs and birds, which can all serve as paratenic hosts. Based on our results, we suggest that cats in urban areas should be considered as a serious potential zoonotic threat. Implementation of proper veterinary control and wider education on the topic is recommended.
\end{abstract}

Keywords: domestic cat; Felis catus; disease transmission; Toxocara cati; endoparasites; urban ecosystems; PCA; prevalence

\section{Introduction}

Environmental parasitic contamination depends on several factors including global warming, increased industrialization, urbanization and biodiversity loss [1,2]. It is assumed that pathogens are likely to thrive in the near future, mainly due to increased urbanization and growth of the human population. The dominant pathogens will be within the group of which transmission is density-dependent and/or of hosts, which are well adapted to urban environments [2]. In addition, higher temperatures in urban areas and overall global warming might increase for some parasites their 
growth, reproduction and even resilience [3-5]. Currently over 4 billion people live in urban areas, which accounts for $55 \%$ of the population; by 2030 , it is estimated that the urban human population will rise to $68 \%$ meaning that two-thirds of the world's population will live in cities [6]. Consequently, millions of people are also expected to migrate, often accompanied by pets. Density-dependent transmission of zoonotic parasites is expected to increase with high population densities and ownership of companion animals. Increased travel activity of people and animals all over the world may bring the possibility of transmission of many parasites, including exotic ones [7-9].

Among pets, the domestic cat (Felis catus) is one of the most common and widely distributed in the world [10]. According to FEDIAF (The European Pet Food Industry) [11] it has been estimated that Europe is inhabited by over 103 million cats and the European Union countries by over 75 million. Over 6 million cats live in Poland alone with 32\% of households owning at least one cat [11]. Cats play an important role as companion animals but also are traditionally used to control rodent pests, especially in rural areas and in many developing countries [12,13]. Many cats have outdoor access to roam freely. This can pose a potential multidimensional health threat. Cats can contaminate the environment with various pathogens including parasitic, bacterial, fungal and viral elements that can be transmitted to humans $[1,2,14]$. Moreover, interactions with sympatric wildlife may result in spillover of parasites from domestic cats [14]. For example, Bartonella spp., Toxoplasma gondii and feline immunodeficiency virus (FIV) can be transmitted from domestic cats to mountain lions (Puma concolor) and bobcats (Lynx rufus) [15] while feline leukemia virus (FeLV) is transmittable to Iberian lynx (Lynx pardinus) [16].

Cats can be infected by numerous endoparasites, including protozoa and helminths $[17,18]$ that not only cause diseases in cats but also are of zoonotic significance. More than $75 \%$ of human disease is of zoonotic origin and from both wildlife and domestic animals [19]. For example, T. gondii, which is probably the most widespread and prevalent parasitic protozoan of major importance to public health. The prevalence of this zoonotic parasite is reported worldwide [13-15]. One of the possible infection routes is by ingestion of oocysts, which are shed by domestic and wild felids [20].

In the case of nematodes such as Toxocara cati (which are responsible for human visceral larva migrans VLM and ocular larva migrans OLM), ingestion by humans of eggs or larvae can lead to zoonotic toxocarosis $[17,21]$. Eggs of $T$. cati are dispersed via the animal's feces in the environment and mature in soil [7]. Eggs of Toxocara spp. are the most frequently found helminth eggs in diagnostic fecal samples of dogs and cats in Germany [8]. The contamination by the eggs of geohelminths such as Toxocara, Ascaris, Trichuris and Ancylostoma can reach up to $40 \%$ of sandy playgrounds in Hanover [22] and recreational areas in Poland [23]. Additionally, in Poland, seroprevelance of human toxocarosis has been reported in up to $75.6 \%$ sera samples [24]. Humans may also become infested with zoonotic cestodes from cats such as Dipylidium caninum or Echinococcus multilocularis $[1,18]$. There are many reports of D. caninum infections in children due to ingestion of infected fleas [17].

Overall, the prevalence of endoparasites of cats in Europe has been found to vary between $20 \%$ and $40 \%$ [17]. Several studies report that stray or free-ranging outdoor cats have a higher frequency of parasites than indoor kept cats $[8,14,17]$. In Greece stray cats were 8.8 times more likely to be infected with Ancylostomatidae when compared to owned cats. Similarly, the infection of T. cati was 2.7 times higher for cats living outdoors in comparison to those staying indoors [7]. In addition, cats represent a more important potential reservoir of parasites than domestic dogs [25].

Domestic cats can be infected by parasites whose life cycles involve transmission from the soil, prey or other carnivores $[1,14,18]$; consequently they can serve as a potential threat to other companion animals, wildlife and people living in the same environment. Therefore, it is of great importance to carry out further research into parasitic infections in domestic cats. Urban and peri-urban areas should be of particular interest in the context of transmission of parasitic diseases. Both environments can be attractive to wild animals, which can easily adapt and participate in parasitic vector-borne infections. For example, the stone marten (Martes foina) or red fox (Vulpes vulpes) can play an important role for transmission of echinococcosis and capillarosis to companion animals [1,26,27]. 
The aim of this study was to investigate the prevalence of endoparasites in outdoor cats in urban areas of Kraków city. The present study provides analyses of potential factors such as age and sex of the cat as well type of the habitat and diet of the cats, which might reflect the infestation of specific parasites.

\section{Materials and Methods}

\subsection{Study Area}

The study was conducted on domestic cats collected as road kills in Kraków metropolitan area, in Southern Poland. Kraków is the second largest city in Poland with a total surface area of $327 \mathrm{~km}^{2}$ and human population over 769,000 (as stated for year 2018) [28]. It is also a popular tourist destination with 7.6 million visiting tourists per year. Built-up and urbanized areas constitute over $46 \%$ of the city. The city core is strongly urbanized while the peripheral districts are mostly composed of blocks of flats and detached houses with patches of green areas. Green areas are more dominant in suburban parts of the city and a large proportion of the city is still used for agricultural purposes with arable land, orchards, meadows and pastures covering $44 \%$ of total city area. Thus, we classified the locations of collected road killed cats into urban and suburban habitats. The estimated number of stray cats in Kraków is over 2400 [29].

\subsection{Data Collection and Parasitological Analysis}

Data were obtained from road-killed cats $(n=81)$, which had been collected by the "Wild Rescue" company ('Dzikie Pogotowie Maciej Lesiak') with the permission of the local municipality. Animals were collected between November 2011 and April 2013. Cats were weighed with precision of $\pm 1 \mathrm{~g}$. We identified sex and age (based on teeth wear) of the individuals. A total of 81 cats (53 males and 28 females) were examined. There were 49 cats in age group 1-2 years old and 32 individuals aged above 2 years. All collected cats were examined by necropsy. Prior to examination all samples were frozen at $-85^{\circ} \mathrm{C}$ for at least two weeks [30] in order to stop development of parasitic forms dangerous to humans, namely Echinococcus sp., which occurs more frequently in Poland especially in the red fox [31]. Necropsies were made according to the method appropriate for parasitological study, e.g., [32,33]. We checked the abdominal cavity and the internal organs including stomach, digestive system, kidney, liver, heart and lungs (scraping of the mucosa of intestine, cutting the organs into small pieces and submerging them in pepsin enzyme). The fecal samples for presence of Protozoan oocysts were examined using the McMaster method with saturated sugar solution. The parasites were preserved in $75 \%$ ethanol with $5 \%$ glycerol addition, then were mounted and cleared with lactophenol. Tapeworms were identified to the lowest possible taxonomic level. Parasites biodiversity was determined based on morphological features [34]. The parasitic infection was expressed as prevalence of infection (number of cats infected with parasites/total number of examined cats $\times 100 \%$ ) and intensity of infection (mean number of parasite individuals per an infected cat).

\subsection{Diet Analysis}

Out of 81 cats' stomachs, 63 contained food remains, and the rest were empty or contained only cat hair. Dried stomach content was weighed and divided into the following food categories: rodents, soricomorphs, birds, invertebrates, anthropogenic food and plant material. Prey species were identified based on remains of hair, feathers and bones using keys and reference material stored as a collection belonging to the Institute of Environmental Sciences Jagiellonian University. Mammals were identified to species or genus based on their bones, teeth [35] and hair [36]. Birds were identified to order based on feathers [37]. Diet of cats was expressed as frequency of occurrence in stomachs \%FO (number of stomachs with one food category/total number of examined stomachs $\times 100 \%$ ). 


\subsection{Statistical Analysis}

The 95\% confidence intervals (CI) of the prevalence values were estimated according to [38] including continuity correction. The non-parametric Mann-Whitney U test was performed in order to reveal significant differences in the intensity of infection of the two most common parasites (i.e., Toxocara cati and Taenia taeniaeformis) between urban and suburban areas. Separate principal component analyses (PCA) based on correlation matrix were applied to show the association of parasites to particular groups of cats. The groups included division of cats according to: (1) sex and age, (2) sex and season, (3) sex and habitat and (4) habitat and age. Matrices for analyses consisted of averaged frequencies of a given parasite in particular groups. The Mantel test [39] was performed to determine the relationship and statistical correlation between the two matrices of similarity, i.e., cats' diet similarity matrix and parasite similarity matrix. The input matrices were based on the mean frequencies of food categories/parasites in groups of cats for particular combinations: season $\times$ sex $\times$ age. Finally, a seriation of all parasites (presence/absence values) recorded in cats sorted according to their weight was performed using a constrained algorithm [40]. The statistical calculations were performed using PAST 3.25 [41].

\section{Results}

\subsection{Prevalence of Endoparasites}

Overall parasites were detected in $50(=62 \%)$ out of the 81 cats. Five cats $(6 \%)$ were infected by one parasite. No Echinococcus multilocularis or Cystoisospora were detected in the examined cats. Toxocara cat $i$ was the most prevalent parasite in the examined cats $(n=36,44.44 \%)$, followed by Taenia taeniaeformis $(n=34,41.98 \%)$, Ancylostoma tubaeformae $(n=17,20.99 \%)$, Dipylidium canininum $(n=5$, $6.17 \%)$ and Toxascaris leonina $(n=3,3.70 \%)$. Mesocestoides sp. was identified in two cats, similarly Eucoleus aerophilus (Table 1).

Table 1. Prevalence (\%) and intensity of parasitic infections of studied cats.

\begin{tabular}{ccccc}
\hline Endoparasite & $\begin{array}{c}\text { N Infected, Prevalence } \\
\text { of Infection (\%) }\end{array}$ & $\begin{array}{c}\text { Mean Intensity } \\
\text { of Infection }\end{array}$ & Range of Infection & $\begin{array}{c}\text { 95\% C.I. } \\
\text { Upper }\end{array}$ \\
\hline Toxocara cati & $36(44.44)$ & 12.22 & $1-81$ & 34.54 \\
Toxascaris leonina & $3(3.70)$ & 1.00 & 1 & 55.87 \\
Ancylostoma tubaeformae & $17(20.99)$ & 7.18 & $1-12$ & 13.18 \\
Taenia taeniaeformis & $34(41.98)$ & 6.12 & $1-32$ & 31.27 \\
Dipylidium caninum & $5(6.17)$ & 2.80 & $1-7$ & 53 \\
Mesocestoides sp. & $2(2.47)$ & 1.00 & $1-4$ & 0.43 \\
Eucoleus aerophilus & $2(2.47)$ & 2.50 & & 0.43 \\
\hline
\end{tabular}

Overall 14.81\% (12/81) of the examined cats had been infected by one parasite. Among other individuals 45 cats $(55.56 \%), 11(13.58 \%)$ and $1(1.23 \%)$ harbored two, three and four different parasites, respectively (Table 2 ).

Table 2. Prevalence (\%) of mixed endoparasite infections in cats.

\begin{tabular}{|c|c|c|c|}
\hline \multirow{2}{*}{ Mixed Endoparasite Infections } & \multirow{2}{*}{ N Infected, Prevalence of Infection (\%) } & \multicolumn{2}{|c|}{ 95\% C.I. } \\
\hline & & Lower & Upper \\
\hline T. cati + T. taeniaeformis & $24(29.63)$ & 20.26 & 40.96 \\
\hline T. cati + A. tubaeformae & $10(12.35)$ & 6.40 & 21.99 \\
\hline T. cati + T. leonina & $1(1.23)$ & 0.06 & 7.63 \\
\hline T. cati + D. caninum & $3(3.70)$ & 0.96 & 11.18 \\
\hline T. cati + Mesocestoides sp. & $2(2.47)$ & 0.43 & 9.46 \\
\hline T. cati + E. aerophilus & $1(1.23)$ & 0.06 & 7.63 \\
\hline T. cat + T. taeniaeformis + A. tubaeformae & $10(12.35)$ & 6.40 & 21.99 \\
\hline T. cati $+T$. leonina $+T$. taeniaeformis & $1(1.23)$ & 0.06 & 7.63 \\
\hline T. cat $i+T$. leonina + A. tubaeformae + T. taeniaeformis & $1(1.23)$ & 0.06 & 7.63 \\
\hline T. taeniaeformis + A. tubaeformae & $4(4.94)$ & 1.59 & 12.84 \\
\hline
\end{tabular}


The cats collected from urban and suburban areas of Kraków city were represented by 33 and 48 individuals respectively. As many as seven parasite species were detected in cats from the suburban area, whereas six were detected from the urban habitats. Apart from Eucoleus aerophilus, the prevalence of each parasite was greater in suburban compared to urban areas (Table S1). The intensity of infection with Taenia taeniaeformis proved to be significantly higher in cats collected from suburban area (Figure 1). The intensity of infection with the second most common parasite, i.e., Toxocara cati, was also higher in suburban areas compared to urban ones but no significant differences were found (Mann-Whitney test; $p>0.05)$.
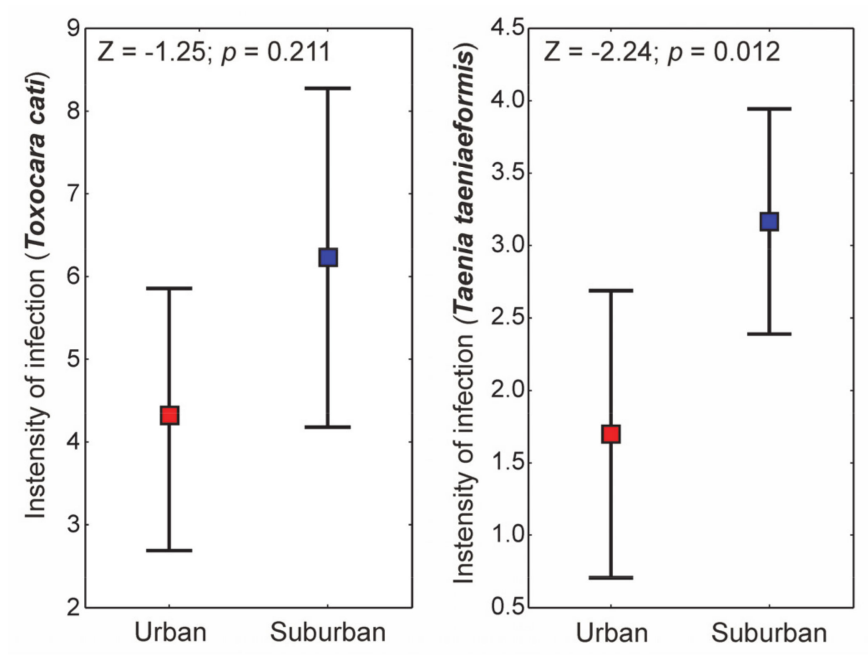

Figure 1. Whisker plots (mean $\pm \mathrm{SE}$ ) of intensity of infection in the two most common parasites of cats in urban and suburban areas. The results of Mann-Whitney $U$ tests are provided in the inset of the graph.

\subsection{Diet Analysis}

In examined material, 63 cats had identifiable content in their stomachs, in which we identified 43 vertebrate prey items: rodents (three species), soricomorphs (two species) and birds (two orders), respectively (Table 3). The most frequently consumed prey species (31 individuals) was the common vole (Microtus arvalis). Other prey species were not numerous (no more than three individuals) and included the bank vole (Myodes glareolus), mice (Apodemus spp.), common shrew (Sorex araneus), pygmy shrew (Sorex minutus) and birds from Columbiformes and Passeriformes. Anthropogenic food was found in $65 \%$ of examined stomachs. The diet of the cats did not differ between males and females. Cats aged 1-2 years old consumed the majority of identified vertebrate prey items (37 of 43 prey individuals). Similarly cats collected in suburban areas consumed more prey than cats from the urban habitats (38 of 43 prey individuals; Table 3).

Table 3. Food categories in cats' diet based on examined stomachs. $n$-number of stomachs with content, $\mathrm{FO}-$ number of stomachs containing food category.

\begin{tabular}{ccccccc}
\hline \multirow{2}{*}{ Food Categories } & \multicolumn{2}{c}{ Urban $n=\mathbf{2 6}$} & \multicolumn{2}{c}{ Suburban $n=37$} & \multicolumn{2}{c}{ Total $n=63$} \\
& FO & $\mathbf{\% F O}$ & FO & $\mathbf{\% F O}$ & FO & \%FO \\
\hline rodents & 4 & 15.4 & 11 & 29.7 & 15 & 23.8 \\
soricomorphs & - & - & 3 & 8.1 & 3 & 4.8 \\
birds & 2 & 7.7 & 3 & 8.1 & 5 & 7.9 \\
invertebrates & 2 & 7.7 & 3 & 8.1 & 5 & 7.9 \\
anthropogenic food & 20 & 76.9 & 21 & 56.8 & 41 & 65.1 \\
plant material & 12 & 46.2 & 23 & 62.2 & 35 & 55.6 \\
\hline
\end{tabular}




\subsection{Differentiation in the Occurrence of Parasites in Cats and Its Relationship with Diet}

Occurrence and frequency (\%) values of endoparasite infections in cats in relation to age, sex, habitat and season are provided in the Supplementary Materials (Tables S1-S4). In general, Eucoleus aerophilus and Dipylidium caninum were more associated with young cats (1-2 years old) regardless of their sex, whereas Taenia taeniaeformis and Mesocestoides sp. occurred more frequently in both male and female adult cats (Figure 2A).

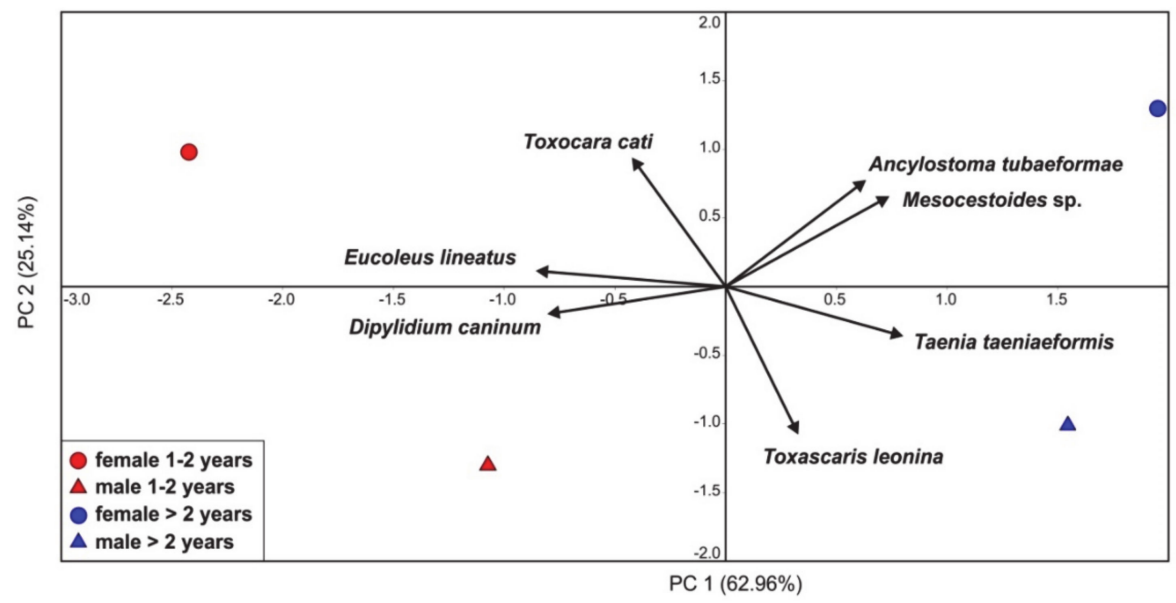

(A)

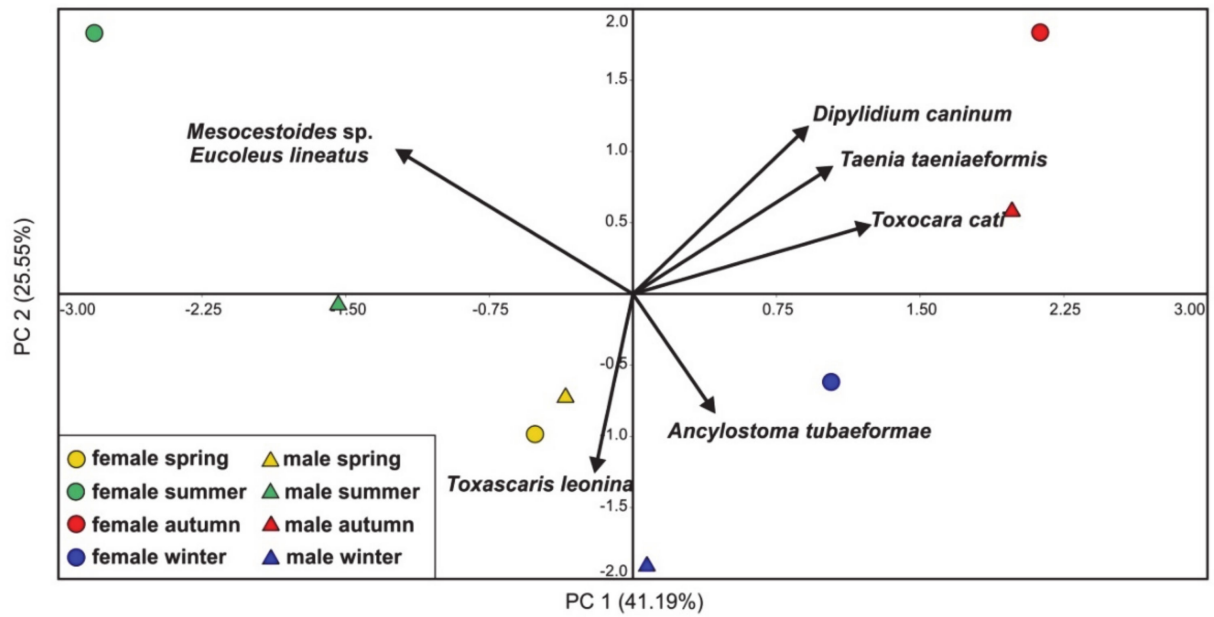

(B)

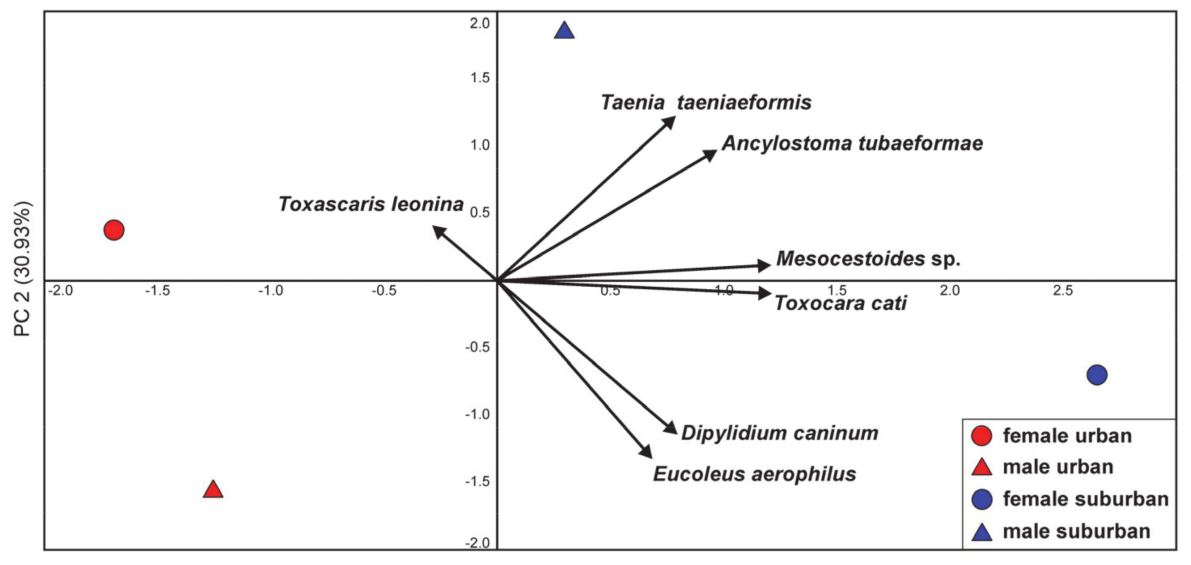

(C)

Figure 2. Cont. 


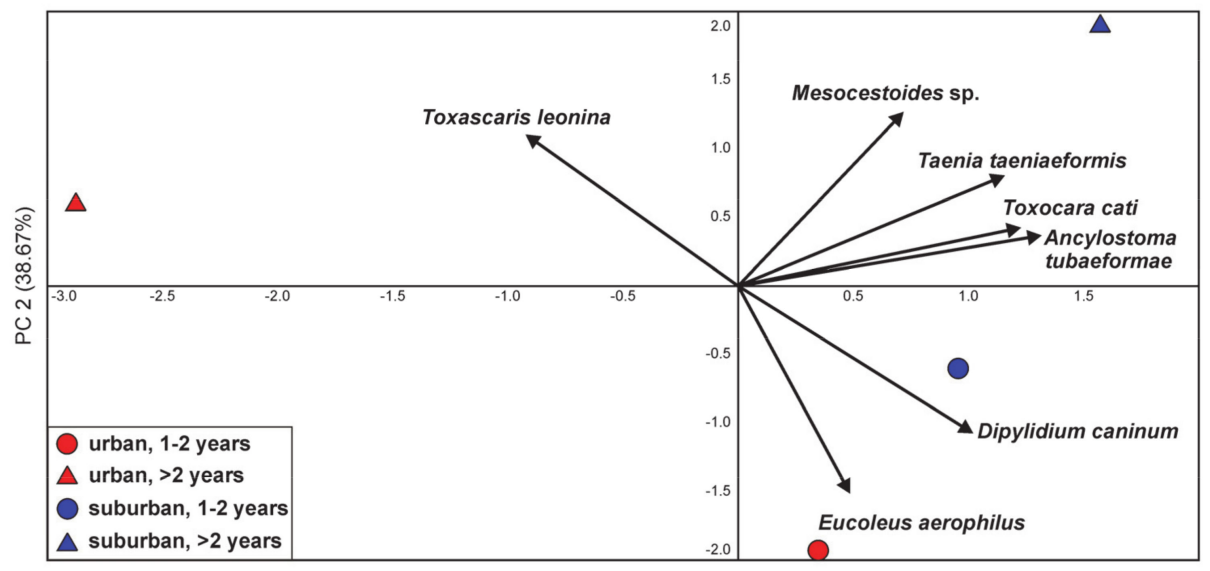

(D)

Figure 2. Biplot of the first two axes of the principal component analysis (PCA) of the groups of cats and parasites in relation to (A) cats' sex and age, (B) cats sex and season, (C) cats sex and habitat and (D) habitat and cats age. The percentage of variance explained by the principal components is provided in parentheses.

Regardless of the sex, parasite composition depended considerably on the season. Mesocestoides sp. and Eucoleus aerophilus were strongly associated with the summer season; and Taenia taeniaeformis, Dipylidium caninum and Toxocara cati with the autumn season (Figure 2B). With regards to sex of the examined cats and habitat where they were found, most of the parasites, with the exception of Toxascaris leonina, were more associated with male and female cats from a suburban habitat (Figure 2C). There was a clear association of Eucoleus aerophilus and Dipylidium caninum with younger cats regardless of the habitat they lived in, whereas Mesocestoides sp., Taenia taeniaeformis, Ancylostoma tubaeformae and Toxocara cati were mostly associated with older cats from suburban habitats (Figure 2D).

The results of the Mantel test showed a significant correlation $(R=0.25, p<0.05)$ between cats' diet similarity and parasite similarity (Figure 3 ). This indicates that the similarity in parasite composition increased with increased similarity of cats' diet.

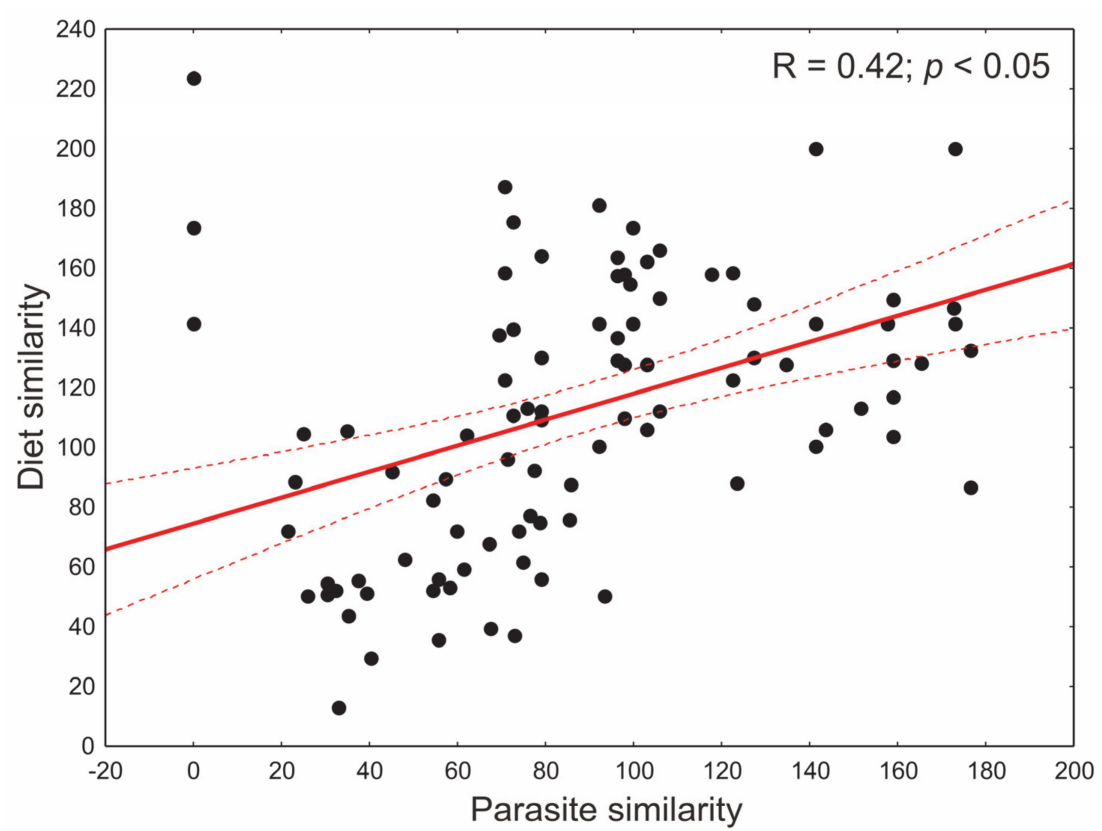

Figure 3. Results of the Mantel test. The correlation between cats' diet similarity and parasite similarity. Pearson correlation coefficient as well as regression line with $95 \%$ confidence interval are provided. 
We found no clear association between cats' weight and presence of parasites (Figure 4).

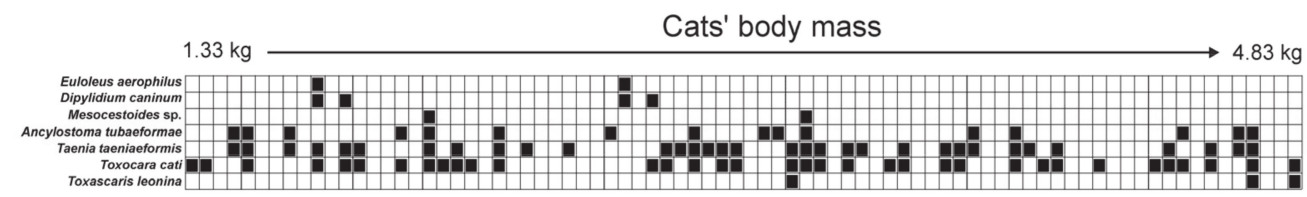

Figure 4. The seriation diagram using a constrained algorithm of parasites (presence/absence values) recorded in cats sorted according to their body mass.

\section{Discussion}

The present study provided a detailed view of the gastrointestinal parasitism of domestic cats in an urban area of Poland. Overall, the prevalence of parasitic infestation of the cats was $62 \%$. Similarly, high levels of parasite prevalence were recorded in recent studies conducted worldwide. For example, the occurrence of infection in India (Mumbai) was 77.22\% [42], in Kenya 73.2\% [13], in United Arab Emirates (Dubai) 87\% [43], in Iran 94\% [44] and 57.9\% in Malaysia [45]. In European countries the overall prevalence of parasite infestation of cats was 30.8\% [46]. Lower prevalence levels were recorded in The Republic of Korea 39.8\% [47], in the USA 24.5\% [9] and Brazil 18.1\% [48]. However, it is important to indicate the status of the cat. In general, stray or cats with outdoor access have higher infection levels in comparison to cats living indoor [14].

In the present study, Cystoisospora were not detected in examined cats. This could be explained by the age of the examined cats, which were at least 1 year old. Coccidiosis has higher prevalence in younger cats $(6-12$ months) $[9,49]$ and in older cats lower prevalence is explained by acquired immunity and better resilience [50]. The most frequently recorded parasite in the examined cats was Toxocara cat $i$ with an overall prevalence $44.44 \%$. It may suggest high distribution of $T$. cati eggs in outdoor environments. This ascarid is known for having a global distribution, which is mainly due to high resistance of eggs in extreme conditions [46]. Moreover, transmammary transmission increases infestation among young cats [51]. In our study both age groups of cats had a prevalence of this parasite over $40 \%$. Information of such high prevalence of this zoonotic parasite is important with regard to public health. High prevalence of $T$. cati in cats might be explained by high predation and consumption of paratenic hosts such as rodents and birds [25]. In the examined cats the majority of prey were rodents including the common vole (M. arvalis), and Apodemus spp. followed by soricomorphs and birds. All may act as reservoirs for numerous parasites and consequently play an important role in circulation of infections among other hosts including cats and humans [1,2,43]. Species of rodents identified in our study (M. arvalis, M. glareolus and Apodemus spp.) have been reported to be infected by Toxocara spp. in urban habitats [52]. In peri-urban areas, the abundance of wildlife species is higher. Domestic cats, allowed to roam freely in such sites, are more vulnerable to being infected and participate in further transmission. In general, the parasitic prevalence in cats from suburban areas was higher than in the individuals living in the city urban core. In particular, infestation by T. cati was more associated with cats living in suburban areas indicating their outdoor access (Figure 2C,D).

The other ascarid infecting cats, Toxascaris leonina, was positive in $3.70 \%$ ( $n=3$ cats). The majority of studies from Europe have indicated a rather low prevalence of this nematode $(0.1-0.3 \%)[7,17,53]$ but in Hungary, this nematode prevalence in examined cats was 7.2\% [49]. In addition, T. leonina has been recorded in many canid and felid species. Cats can be infected by ingesting either eggs or rodents, which can play the role of optional intermediate host [54]. T. leonina has the potential to cause human disease as emerging zoonosis [1].

Among cestodes, a high prevalence (41.98\%) was detected in cats of taeniid infection by Taenia taeniaeformis. In our study this parasite was associated more with older cats living in the suburbs. This tapeworm can use rodents in the life cycle, the dominant prey of cats in our study. This coincides with results that were shown by $[43,49]$ who indicated that $T$. taeniaeformis had the lowest prevalence in the city centre compared to suburb districts and linked this fact to lower abundance of rodents. 
It is also argued by $[9,17,49]$ that detection of cestodes by coproscopy results in much lower prevalence range $1-3 \%$ (e.g., [9,46,53]) than necropsy: 60\% [44] and 17\% [43]. Thus, it is recommended to include this fact in further analysis, in particular as it is disputed that eggs from Taenia and Echinococcus cannot be distinguished and that "cats excreting taeniid eggs must be initially considered as possibly infected with Echinococcus multilocularis" [53].

The hookworm species detected in domestic cats was Ancylostoma tubaeforme. The overall prevalence of this parasite in cats was $20.99 \%$. It occurred more frequently in suburban cats. This again could be associated with cats feeding on rodents, which serve as paratenic hosts of the parasite [18]. Hookworms are common parasites of cats and dogs but have a potential role as a source of zoonotic disease, being known as a cause of cutaneous larva migrans $[55,56]$. Our results are consistent with some studies of cats, e.g., the prevalence of ancylostomatidosis was $26 \%$ in Hungary [49] and $21 \%$ in the United Arab Emirates [43]. In India the prevalence of Ancylostoma spp. detected in cats was $52.78 \%$ and associated with mainly older individuals (above one year old) [42]. In the USA, Brazil, Kenya and several European countries the prevalence of hookworms ranged between $0.5 \%$ and $9.7 \%[7,9,13,21,46,48,53]$.

Tapeworms belonging to the species Dipylidium caninum $(6.17 \%, n=5$ cats) were found at a lower prevalence compared to other parasites detected in the examined cats. This is consistent with other results $[17,48,57]$. However, there are reports of high prevalence of this parasite as in the studies conducted in Belgrade where $22 \%$ of cats were infected by D. caninum [21]. In the life cycle this cestode uses fleas as intermediate hosts. Humans can be infected by ingestion of infected fleas most commonly brought home by cats [18].

In the present study two parasite species Mesocestodes sp. and Eucoleus aerophilus were detected in low prevalence (both $2.47 \% n=2$ cats infected). Mesocestoides sp. are not commonly reported in literature and their prevalence in infected cats does not exceed 1\% [9] but in Iran 78\% of examined cats were positive for this parasite [44] The life cycle of Mesocestoides sp. is not clearly defined: it is possible cats get infected through ingestion of vertebrate intermediate hosts containing tetrathyridia [18].

In our study, we did not find pulmonary nematodes in the examined cats except for Eucoleus aerophilus (Trichurida, Trichinellidae, syn. Capillaria aerophila). Together with $D$. caninum these two parasites were more associated with younger cats (1-2 years old) regardless of the habitat they occupied. Consistent with research of [46] it is reported that wildlife species like the red fox, have a direct impact on dispersion of lung capillariosis in cats $[27,49]$. The infection of cats can be also explained by ingestion of paratenic hosts such as rodents, soricomorphs and birds [58]. In recent years, more attention has been paid to pulmonary nematodes due to their high pathogenicity [59]. Lung nematodes Aelurostrongylus abstrusus (Strongylida: Angiostrongylidae) were commonly reported in cats across Europe $[27,46]$ and together with E. aerophilus are currently considered the most important causes of parasite-induced respiratory infection in felids [27]. Recently, the pulmonary nematode Troglostrongylus brevior (Strongylida: Crenosomatidae) has also been detected in domestic cats [60].

Although we analyzed the effect of season on the prevalence of parasites in cats, it must be emphasized that the examined cats could have been infected earlier and it is not possible to indicate the beginning of the parasitic infestation. In our study we recorded higher prevalence of parasitic infestation of examined cats in both summer and autumn seasons. This could be associated with better access to wildlife prey as well as the breeding season of the cats followed by a higher prevalence in newborn kittens [9]. Stray or outdoor cats are likely to be infested with parasites [7,9,14,25,43], however, even owned cats are at risk of being infested. A recent survey [8] revealed that domestic cats are commonly not dewormed properly by their owners who might be even reluctant to use anthelmintics as they are afraid of using chemical treatments. Moreover, pet owners often have insufficient knowledge about zoonoses transmitted by cats.

In the future, the expanding contact between humans, domestic animals and wildlife will likely have an impact on zoonotic helminth spread [61]. Considering that cats and dogs are the most 
numerous pets, and that often they are in very close contact with their owners, this should bring attention to the higher risk of possible transmission of zoonoses [21,61].

\section{Conclusions}

Our data indicate a high prevalence of endoparasite infections in free ranging cats in urban and suburban areas in Poland. Toxocara cati and A. tubaeformae, associated with zoonotic diseases, were among the most prevalent parasites in the examined cats. This should be considered important information about possible health risks and the need for implementation of proper veterinary control. Outdoor access and uncontrolled roaming of cats increases the risk of parasitic infections. This includes also cats that feed on small vertebrates. In suburban areas the probability of interspecific parasitic transmissions is more common in cats. Thus, it is crucial to educate the owners about possible exposure to zoonotic diseases through their pets.

Supplementary Materials: The following are available online at http://www.mdpi.com/2076-2615/10/4/748/s1, Table S1: Occurrence, mean intensity, and prevalence (\%) with 95\% CI of parasitic infections of cats in different habitat types; Table S2: Occurrence, mean intensity, and prevalence (\%) with $95 \%$ CI of parasitic infections of cats in different sex groups; Table S3: Occurrence, mean intensity, and prevalence (\%) with $95 \%$ CI of parasitic infections of cats in different age groups; Table S4: Occurrence, mean intensity, and prevalence (\%) with $95 \% \mathrm{CI}$ of parasitic infections of cats in different seasons.

Author Contributions: Conceptualization, I.A.W.; Formal analysis, K.R.; Investigation, I.A.W., S.K. and A.M.P.; Writing—original draft, I.A.W., S.K. and A.M.P.; Writing—review and editing, I.A.W., S.K., A.M.P. and K.R. All authors have read and agreed to the published version of the manuscript.

Funding: This research was partially funded by Jagiellonian University, grant number DS 756. The APC was co-funded by Jagiellonian University and University of Agriculture in Kraków.

Acknowledgments: We would like to thank 'Dzikie Pogotowie Maciej Lesiak' company for help with collecting the samples for our study. We thank the reviewers and associate editor for their valuable comments and suggestions that allowed us to greatly improve the first version of this manuscript.

Conflicts of Interest: The authors declare no conflict of interest.

\section{References}

1. Mackenstedt, U.; Jenkins, D.; Romig, T. The role of wildlife in the transmission of parasitic zoonoses in peri-urban and urban areas. Int. J. Parasitol. Parasites Wildl. 2015, 4, 71-79. [CrossRef] [PubMed]

2. Cable, J.; Barber, I.; Boag, B.; Ellison, A.R.; Morgan, E.R.; Murray, K.; Pascoe, E.L.; Sait, S.M.; Wilson, A.J.; Booth, M. Global change, parasite transmission and disease control: Lessons from ecology. Philos. Trans. R. Soc. Lond. B Biol. Sci. 2017, 372, 20160088. [CrossRef] [PubMed]

3. Koelle, K.; Pascual, M.; Yunus, M. Pathogen adaptation to seasonal forcing and climate change. Proc. R Soc. Lond. B Biol. Sci. 2005, 272, 971-977. [CrossRef] [PubMed]

4. Studer, A.; Thieltges, D.W.; Poulin, R. Parasites and global warming: Net effects of temperature on an intertidal host-parasite system. Mar. Ecol. Prog. Ser. 2010, 415, 11-22. [CrossRef]

5. Ogden, L.E. Climate change, pathogens, and people. Bioscience 2018, 68, 733-739. [CrossRef]

6. Ritchie, H.; Roser, M. Urbanization. Our World in Data. Available online: https://ourworldindata.org/ urbanization (accessed on 27 February 2020).

7. Symeonidou, I.; Gelasakis, A.I.; Arsenopoulos, K.; Angelou, A.; Beugnet, F.; Papadopoulos, E. Feline gastrointestinal parasitism in Greece: Emergent zoonotic species and associated risk factors. Parasit Vectors 2018, 11, 227. [CrossRef]

8. Strube, C.; Neubert, A.; Springer, A.; von Samson-Himmelstjerna, G. Survey of German pet owners quantifying endoparasitic infection risk and implications for deworming recommendations. Parasit Vectors 2019, 12, 203. [CrossRef]

9. Nagamori, Y.; Payton, M.E.; Looper, E.; Apple, H.; Johnson, E.M. Retrospective survey of parasitism identified in feces of client-owned cats in North America from 2007 through 2018. Vet. Parasitol. 2020, 277, 109008. [CrossRef]

10. Silva-Rodriguez, E.A.; Sieving, K.E. Influence of Care of Domestic Carnivores on Their Predation on Vertebrates. Conserv. Biol. 2011, 25, 808-815. [CrossRef] 
11. FEDIAF Facts \& Figures. Available online: http://www.fediaf.org/52-dcs-statistics (accessed on 15 December 2019).

12. Friedmann, E.; Son, H. The human-companion animal bond: How humans benefit. Vet. Clin. North. Am. Small Anim. Pract. 2009, 39, 293-326. [CrossRef]

13. Nyambura Njuguna, A.; Kagira, J.M.; Muturi Karanja, S.; Ngotho, M.; Mutharia, L.; Wangari Maina, N. Prevalence of Toxoplasma gondii and other gastrointestinal parasites in domestic cats from households in Thika region, Kenya. Biomed. Res. Int. 2017, 2017,1-6. [CrossRef] [PubMed]

14. Chalkowski, K.; Wilson, A.E.; Lepczyk, C.A.; Zohdy, S. Who let the cats out? A global meta-analysis on risk of parasitic infection in indoor versus outdoor domestic cats (Felis catus). Biol. Lett. 2019, 15, 20180840. [CrossRef] [PubMed]

15. Carver, S.; Bevins, S.N.; Lappin, M.R.; Boydston, E.E.; Lyren, L.M.; Alldredge, M.; VandeWoude, S. Pathogen exposure varies widely among sympatric populations of wild and domestic felids across the United States. Ecol. Appl. 2016, 26, 367-381. [CrossRef] [PubMed]

16. Meli, M.L.; Cattori, V.; Martínez, F.; López, G.; Vargas, A.; Simón, M.A.; Zorrilla, I.; Muñoz, A.; Palomares, F.; López-Bao, J.V.; et al. Feline leukemia virus and other pathogens as important threats to the survival of the critically endangered Iberian lynx (Lynx pardinus). PLoS ONE 2009, 4. [CrossRef]

17. Beugnet, F.; Bourdeau, P.; Chalvet-Monfray, K.; Cozma, V.; Farkas, R.; Guillot, J.; Rinaldi, L. Parasites of domestic owned cats in Europe: Co-infestations and risk factors. Parasit Vectors. 2014, 7, 291. [CrossRef]

18. Little, S.E.; Marrinson, R. Feline Helminths: Recommendations from the Companion Animal Parasite Council. Today's Vet. Pract. 2014, 4, 39-43.

19. Taylor, L.H.; Latham, S.M.; Woolhouse, M.E. Risk factors for human disease emergence. Philos Trans. R. Soc. Lond. B Biol. Sci. 2001, 356, 983-989. [CrossRef]

20. Macpherson, C.N. Human behaviour and the epidemiology of parasitic zoonoses. Int. J. Parasitol. 2005, 35, 1319-1331. [CrossRef]

21. Ilić, T.; Kulišić, Z.; Antić, N.; Radisavljević, K.; Dimitrijević, S. Prevalence of zoonotic intestinal helminths in pet dogs and cats in the Belgrade area. J. Appl. Anim. Res. 2017, 45, 204-208. [CrossRef]

22. Kleine, A.; Springer, A.; Strube, C. Seasonal variation in the prevalence of Toxocara eggs on children's playgrounds in the city of Hanover, Germany. Parasite Vector. 2017, 10, 248. [CrossRef]

23. Bojar, H.; Kłapeć, T. Contamination of soil with eggs of geohelminths in recreational areas in the Lublin region of Poland. Ann. Agric. Environ. Med. 2012, 19, 267-270. [PubMed]

24. Borecka, A.; Kłapec, T. Epidemiology of human toxocariasis in Poland-A review of cases 1978-2009. Ann. Agric. Environ. Med. 2015, 22, 28-31. [CrossRef]

25. Szwabe, K.; Blaszkowska, J. Stray dogs and cats as potential sources of soil contamination with zoonotic parasites. Ann. Agric. Environ. Med. 2017, 24, 39-43. [CrossRef] [PubMed]

26. Kornaś, S.; Wierzbowska, I.A.; Górski, P.; Okarma, H. Occurrence of internal parasites in stone martens (Martes foina) from Cracow and suburbs. Ann. Parasitol. 2013, 59, 203-205. [PubMed]

27. Traversa, D.; Di Cesare, A. Diagnosis and management of lungworm infections in cats: Cornerstones, dilemmas and new avenues. J. Feline Med. Surg. 2016, 18, 7-20. [CrossRef] [PubMed]

28. Statistical Office in Kraków. Available online: https://krakow.stat.gov.pl (accessed on 16 December 2019).

29. KRKNEWS.PL. Available online: https://krknews.pl/ile-kotow-mieszka-w-krakowie-zaskakujace-wynikibadan (accessed on 2 February 2020).

30. Eckert, J.; Deplazes, P. Biological, epidemiological, and clinical aspects of echinococcosis, a zoonosis of increasing concern. Clin. Microbiol. Rev. 2004, 17, 107-135. [CrossRef] [PubMed]

31. Gawor, J. Alveolar echinococcosis in Europe and Poland. Threats to humans. Przegl. Epidemiol. 2016, 70, 281-288.

32. Takeuchi-Storm, N.; Mejer, H.; Al-Sabi, M.N.; Olsen, C.S.; Thamsborg, S.M.; Enemark, H.L. Gastrointestinal parasites of cats in Denmark assessed by necropsy and concentration McMaster technique. Vet. Parasitol. 2015, 214, 327-332. [CrossRef]

33. McDonough, S.P.; Southard, T.L. Necropsy guide for dogs, cats, and small mammals; Wiley: Hoboken, NJ, USA, 2017.

34. Soulsby, E.J.L. Helminths, Arthropods \& Protozoa of Domesticated Animals. In 6th Edition of Mönnig's Veterinary Helminthology \& Entomology; Lea \& Febiger: Philadelphia, PA, USA, 1977.

35. Pucek, Z. Klucz do Oznaczania Ssaków Polski; Państwowe Wydawnictwo Naukowe: Warszawa, Poland, 1984.

36. Teerink, B.J. Hair of West European Mammals: Atlas and Identification Key; Cambridge University Press: Cambridge, UK, 2003. 
37. Dove, C.J.; Koch, S.L. Microscopy of feathers: A practical guide for forensic feather identification. Microsc. Chic. 2011, 59, 51.

38. Newcombe, R.G. Two-Sided Confidence Intervals for the Single Proportion: Comparison of Seven Methods. Stat. Med. 1998, 17, 857-872. [CrossRef]

39. Mantel, N. The detection of disease clustering and a generalized regression approach. Cancer Res. 1967, 27, 209-220. [PubMed]

40. Brower, J.C.; Kile, K.M. Seriation of an original data matrix as applied to palaeoecology. Lethaia 1988, 21, 79-93. [CrossRef]

41. Hammer, Ø.; Harper, D.A.T.; Ryan, P.D. PAST: Paleontological statistics software package for education and data analysis. Palaeontol. Electron. 2001, 4, 1-9.

42. Lavanya, K.; Malkar, S.; Pednekar, R.; Gatne, M. Prevalence of Gastrointestinal Parasites with Special Reference to Zoonotic Parasites in Domestic Cats (Felis catus) in Mumbai, Maharashtra. J. Vet. Pub. Hlth. 2016, 14, 47-49.

43. Schuster, R.K.; Thomas, K.; Sivakumar, S.; O’Donovan, D. The parasite fauna of stray domestic cats (Felis catus) in Dubai, United Arab Emirates. Parasitol. Res. 2009, 105, 125-134. [CrossRef]

44. Hajipour, N.; Imani Baran, A.; Yakhchali, M.; Banan Khojasteh, S.M.; Sheikhzade Hesari, F.; Esmaeilnejad, B.; Arjmand, J. A survey study on gastrointestinal parasites of stray cats in Azarshahr, (East Azerbaijan province, Iran). J. Parasit. Dis. 2015, 40, 1255-1260. [CrossRef]

45. Tun, S.; Ithoi, I.; Mahmud, R.; Samsudin, N.I.; Kek Heng, C.; Ling, L.Y. Detection of Helminth Eggs and Identification of Hookworm Species in Stray Cats, Dogs and Soil from Klang Valley, Malaysia. PLoS ONE 2015, 10, e0142231. [CrossRef]

46. Giannelli, A.; Capelli, G.; Joachim, A.; Hinney, B.; Losson, B.; Kirkova, Z.; Otranto, D. (). Lungworms and gastrointestinal parasites of domestic cats: A European perspective. Int. J. Parasitol. Parasites Wildl. 2017, 47, 517-528. [CrossRef]

47. Lee, S.H.; Ock, Y.; Choi, D.; Kwak, D. Gastrointestinal Parasite Infection in Cats in Daegu, Republic of Korea, and Efficacy of Treatment Using Topical Emodepside/Praziquantel Formulation. Korean J. Parasitol. 2019, 57, 243-248. [CrossRef]

48. Gennari, S.M.; Ferreira, J.I.; Pena, H.F.; Labruna, M.B.; Azevedo, S.D. Frequency of gastrointestinal parasites in cats seen at the University of Sao Paulo Veterinary Hospital, Brazil. Rev. Bras. Parasitol. Vet. 2016, 25, 423-428. [CrossRef]

49. Capari, B.; Hamel, D.; Visser, M.; Winter, R.; Pfister, K.; Rehbein, S. Parasitic infections of domestic cats, Felis catus, in western Hungary. Vet. Parasitol. 2013, 192, 33-42. [CrossRef] [PubMed]

50. Lindsay, D.S.; Todd, K.S., Jr. Coccidia of Mammals. In Parasitic Protozoa, 2nd ed.; Kreier, J., Ed.; Academic Press: New York, NY, USA, 1993; Volume 4, pp. 89-131.

51. Nagamori, Y.; Payton, M.E.; Duncan-Decocq, R.; Johnson, E.M. Fecal survey of parasites in free-roaming cats in northcentral Oklahoma, United States. Vet. Parasitol. Reg. Stud. Rep. 2018, 14, 50-53. [CrossRef] [PubMed]

52. Reperant, L.A.; Hegglin, D.; Tanner, I.; Fischer, C.; Deplazes, P. Rodents as shared indicators for zoonotic parasites of carnivores in urban environments. Parasitology 2009, 136, 329-337. [CrossRef] [PubMed]

53. Becker, A.C.; Rohen, M.; Epe, C.; Schnieder, T. Prevalence of endoparasites in stray and fostered dogs and cats in Northern Germany. Parasitol. Res. 2012,111, 849-857. [CrossRef]

54. Okulewicz, A.; Perec-Matysiak, A.; Buńkowska, K.; Hildebrand, J. Toxocara canis, Toxocara cati and Toxascaris leonina in wild and domestic carnivores. Helminthologia 2012, 49, 3-10. [CrossRef]

55. Lucio-Forster, A.; Bowman, D.D. Prevalence of fecal-borne parasites detected by centrifugal flotation in feline samples from two shelters in upstate New York. J. Feline Med. Surg. 2011, 13, 300-303. [CrossRef]

56. CFSPH Center for Food Security and Public Health. Zoonotic Hookworms. Available online: http: //www.cfsph.iastate.edu (accessed on 28 February 2020).

57. Khalafalla, R.E. A survey study on gastrointestinal parasites of stray cats in northern region of Nile delta, Egypt. PLoS ONE 2011, 6, e20283. [CrossRef]

58. Traversa, D.; Di Cesare, A.; Milillo, P.; Iorio, R.; Otranto, D. Infection by Eucoleus aerophilus in dogs and cats: Is another extra-intestinal parasitic nematode of pets emerging in Italy? Res. Vet. Sci. 2009, 87, 270-272. [CrossRef] 
59. Crisi, P.E.; Aste, G.; Traversa, D.; Di Cesare, A.; Febo, E.; Vignoli, M.; Santori, D.; Luciani, A.; Boari, A. Single and mixed feline lungworm infections: Clinical, radiographic and therapeutic features of 26 cases (2013-2015). J. Feline Med. Surg. 2017, 19, 1017-1029. [CrossRef]

60. Szczepaniak, K.; Leśniak, P.; Studzińska, M.; Roczeń-Karczmarz, M.; Demkowska-Kutrzepa, M.; Junkuszew, A.; Tomczuk, K. Occurrence of larvae of Metastrongyloidea in feaces of cats from southeastern Poland. Med. Weter. 2019, 75, 605-608. [CrossRef]

61. Wells, K.; Gibson, D.I.; Clark, N.J.; Ribas, A.; Morand, S.; McCallum, H.I. Global spread of helminth parasites at the human-domestic animal-wildlife interface. Glob. Chang. Biol. 2018, 24, 3254-3265. [CrossRef] [PubMed]

(C) 2020 by the authors. Licensee MDPI, Basel, Switzerland. This article is an open access article distributed under the terms and conditions of the Creative Commons Attribution (CC BY) license (http://creativecommons.org/licenses/by/4.0/). 